\title{
Determination of Torsion Load and Weight Optimization of a Transport Automobile Chassis Using FEA
}

\author{
Saira Das ${ }^{1}$, Bommanna .K ${ }^{2}$ \\ ${ }^{1,2}$ Department of Mechanical Engineering, T.John College of Engineering, VTU, Bangalore, Karnataka, India
}

\begin{abstract}
This research work aims to perform a torsion and Bending Test on the computational prototype chassis to determine its torsional stiffness and to incorporate a design improvement study and note the effects on the global torsional stiffness of the chassis. The stress, strength and degrees of freedom of the chassis will be investigated. The body shape is fixed and therefore the overall external shape of the chassis must not be altered. The engine bay must remain as open as possible to allow a variety of engines to be fitted.
\end{abstract}

Keywords: finite element analysis, automotive, structure, Chassis

\section{Introduction}

Since the change of economic growth are changing from time to time which leads to the high demand in truck industry mostly in Malaysia. Many industries use the trucks for transportation like agricultures, logistics, etc. But the production and development of truck industries in Malaysia are much depending on depending on foreign technology and even not fulfilling the market demand in costs, performance and transportation efficiency

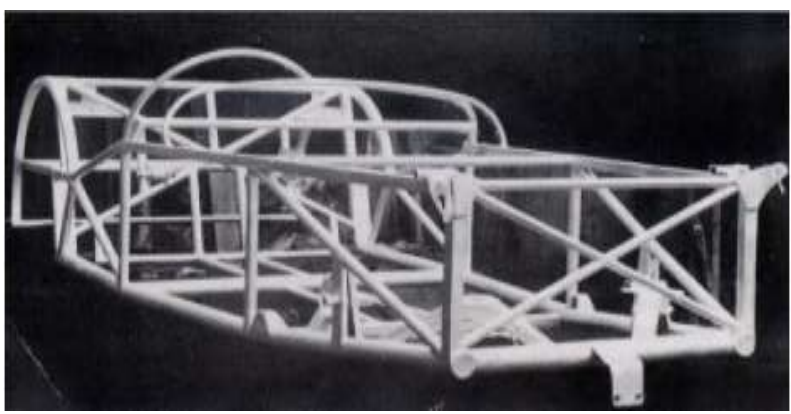

Figure 1: Lotus Mk.1V space frame

\subsection{Types of truck}

There are many types of trucks in the world. Most of the truck manufactures receives truck orders for transportation purposes and their specification is based on size and capacity. Based on this specification there are three types of trucks manufactures in the market, the compact truck, mid size and full size truck.

\subsubsection{Compact truck}

It is the most popular form of pickup trucks in whole world. It is built as a mini version of two axle heavy trucks with a leaf spring suspension on rear wheels, V6 engine using gasoline and conventional cap. It was introduced to North America in the year 1960 by a Japanese manufacturer

\subsubsection{Full size truck}

This type of truck is suitable for carrying heavy loads and for other functions. Most of these trucks can carry $450 \mathrm{~kg}$ in the front bed

\subsubsection{Mid size truck}

In North America trucks are used as passenger cars. They are popular in construction workers, housewives and office workers. Hence, they need a pickup truck with more fuel efficient

\section{Literature Survey}

Dave Anderson and Greg Schade [1] developed a Multi-Body Dynamic Model of the Tractor-Semitrailer for ride quality prediction. The studies involved representing the distributed mass and elasticity of the vehicle structures e.g. frame ladder, the non-linear behaviour of shock absorbers, reproduce the fundamental system dynamics that influence ride and provide output of the acceleration, velocity and displacement measures needed to compute ride quality. There were three main factors contributed in this study. Firstly, the author had come out with the development of an ADAMS multi-body dynamics model for use as a predictive tool in evaluating ride quality design improvement. The model includes frame, cab and model generated from finite element component mode synthesis. Second, the construction and correlation of the model has been developed and followed a multistep process in which each of the major sub-systems were developed and validated to test results prior to corporation in the full vehicle model. Finally, after a series of refinements to the model, the next steps were implemented to obtain an acceptable degree of correlation. The author had managed to evaluate the model's ability to predict ride quality by using accelerations measured in the component, which were then processed through an algorithm to compute an overall ride comfort rating.

I.M. Ibrahim, et.al. [2] Had conducted a study on the effect of frame flexibility on the ride vibration of trucks. The aim of the study was to analyze the vehicle dynamic responses to external factors. The spectral analysis technique was used in

Volume 6 Issue 12, December 2017 


\section{International Journal of Science and Research (IJSR) \\ ISSN (Online): 2319-7064}

Index Copernicus Value (2016): 79.57 | Impact Factor (2015): 6.391

the problem study. Other than that, the driver acceleration response has been weighted according to the ISO ride comfort techniques. From the author point of view, the excessive levels of vibration in commercial vehicles were due to excitation from the road irregularities which led to ride discomfort, ride safety problems, road holding problems and to cargo damage or destruction. Also, it has been found that the frame structure vibrations due to flexibility have a similar effect on the vehicle dynamic behaviour. In order to study the frame flexibility, the author had came out with the truck frame modelled using the Finite Element Method (FEM) and its modal properties have been calculated. Numerical results were presented for the truck, including power spectral densities and root mean square values of the vehicle dynamic response variables. The results show that there was good agreement with the experimental analysis and that modelling technique was a very powerful and economical for the analysis of complex vehicle structures. From the comparison of the responses of the rigid and flexible body models it has been found that the frame flexibility strongly affects the accelerations of both driver and truck body. Therefore, the author suggested that the frame flexibility effects were taken into account in the design of primary, cab and engine suspension systems.

Lonny L. Thomson,[5] had presented his paper on the twist fixture which can measure directly the torsion stiffness of the truck chassis. The fixture was relatively lightweight and portable with the ability to transport and set-up by one person. The extensive testing has been carried out to check on the accuracy of the fixture and found to be within $6 \%$ accuracy. Using the twist fixture design, the author has managed to test on several chassis of different manufacturers. These tests were performed to compare the stiffness values of the different chassis. The results show that the standard errors were below 5\%. Due to this uncertainty in the measured data, small changes in stiffness such as that contributed by the engine cannot be measured with the fixture.

\section{Theoretical Analysis}

\subsection{Vehicle Specifications}

Table 1: Engine Specifications

\begin{tabular}{|c|c|}
\hline Engine & $\begin{array}{c}\text { Turbocharged Diesel Common Rail } \\
\text { (TDCR) engine }\end{array}$ \\
\hline Emission Norms & BS-IV \\
\hline Engine Cylinders & 3 \\
\hline Displacement $($ cc $)$ & 1478 \\
\hline Max Power & 58 bhp @ 3300 rpm \\
\hline Max Torque & 158 Nm @ 1600-2400 rpm \\
\hline Transmission & Manual \\
\hline Clutch & 215 mm dia. Single plate dry, Pot type \\
\hline Gearbox & 5-speed \\
\hline Fuel & Diesel \\
\hline Fuel Tank & 40 Litres \\
\hline
\end{tabular}

\subsection{Structure \& Dimensions}

Table 2: Structural specifications

\begin{tabular}{|c|c|}
\hline Axle Configuration & 4-tyre vehicle \\
\hline Tyres & 185 R 14 - 8 PR \\
\hline Wheelbase $(\mathrm{mm})$ & 2350 \\
\hline Overall Length $(\mathrm{mm})$ & 4485 \\
\hline
\end{tabular}

\begin{tabular}{|c|c|}
\hline Overall Width $(\mathrm{mm})$ & 1620 \\
\hline Overall Height $(\mathrm{mm})$ & 1835 \\
\hline Ground Clearance $(\mathrm{mm})$ & 177 \\
\hline
\end{tabular}

\subsection{Weights}

Table 3: Total weight of the truck

\begin{tabular}{|c|c|}
\hline GVW / GCW (Kg) & 2500 \\
\hline Kerb Weight $(\mathrm{Kg})$ & 1250 \\
\hline Payload $(\mathrm{Kg})$ & 1250 \\
\hline
\end{tabular}

\subsection{Design Load}

Considering two persons traveling in the vehicle with an average weight of $80 \mathrm{~kg}$.

Therefore,

Max. weight of two persons $=2 * 80=160 \mathrm{~kg}$

Total weight applied on the chassis $=2500+160=2660 \mathrm{~kg}$

Total Load applied on the chassis $=2660 * 9.81=26094.6 \mathrm{~N}$

The load is applied on the top face of the chassis and the area is measured using the CAD model created which is $1.172 * 106 \mathrm{~mm} 2$.

Therefore, Pressure $=($ Total Load $) /$ Area

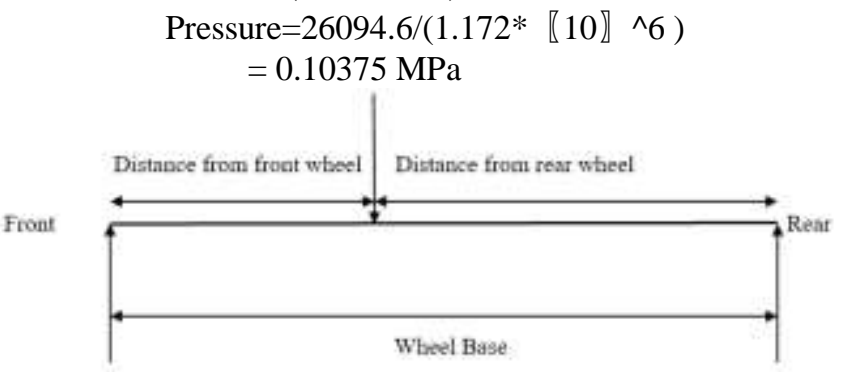

Figure 2: Free Body Diagram of chassis

The center of gravity can be calculated as,

$\mathrm{CG}=2350 * 2 / 3$

$=1566.667 \mathrm{~mm}$

Taking moment at front wheel,

$26094.6 * 1566.667=\mathrm{F} \_\mathrm{R} * 2350$

$\mathrm{F} \_\mathrm{R}=(26094.6 * 1566.667) / 2350$

FR $=17396.404 \mathrm{~N}$

Load on each rear wheel $=8698.202 \mathrm{~N}$

Since there are two wheels on the front axle,

Load on front axle $=26094.6-17396.404$

Load on each front wheel $=8698.196 / 2$

$=4349.098 \mathrm{~N}$

\section{Finite Element Analysis}

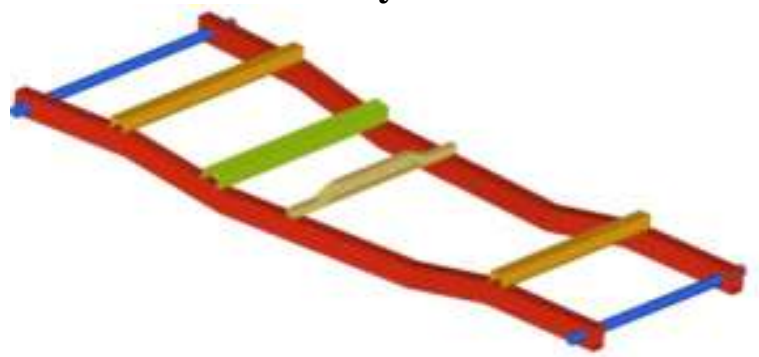

Figure 3: Original CAD model of ladder frame chassis

4.1.1. FE Model with Loads and Boundary Conditions The model is constrained at the Root of the spar to simulate attachment to the fuselage of the selected airplane. The Loads

Volume 6 Issue 12, December 2017 


\section{International Journal of Science and Research (IJSR) \\ ISSN (Online): 2319-7064 \\ Index Copernicus Value (2016): 79.57 | Impact Factor (2015): 6.391}

are applied as shown in the calculations of the previous sections.

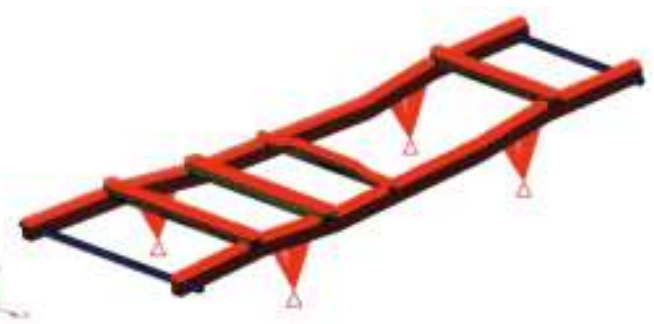

Figure 4: Analysis setup for vehicle moving on a straight road

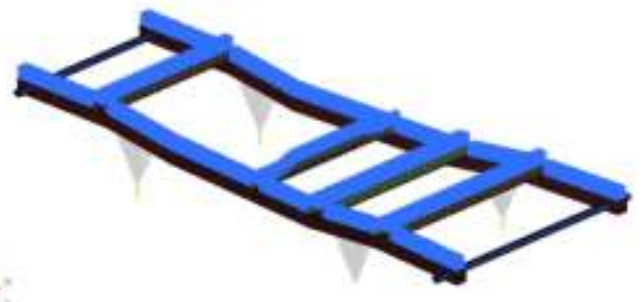

Figure 5: Analysis setup for vehicle taking a left turn

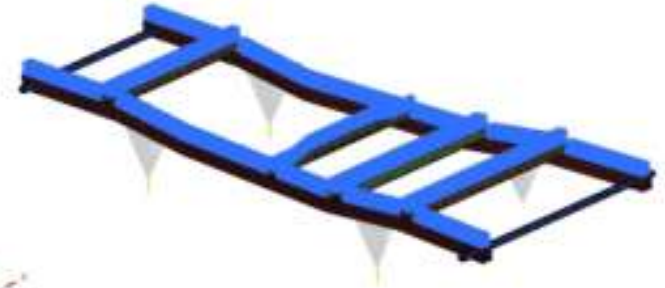

Figure 6: Analysis setup for vehicle taking a right turn

Table 4: Dimensions of the original and modified chassis designs

\begin{tabular}{|c|c|c|c|c|c|}
\hline & $\begin{array}{c}\text { Rail } \\
\text { structure }\end{array}$ & \begin{tabular}{|c|} 
Hat section \\
1 \\
\end{tabular} & Hat section 2 & $\begin{array}{c}\text { Rectangular } \\
\text { section }\end{array}$ & $\begin{array}{c}\text { Circular } \\
\text { section }\end{array}$ \\
\hline Original & \begin{tabular}{|} 
Length: 89 \\
Breadth: \\
98 \\
Thickness: \\
2
\end{tabular} & \begin{tabular}{|c|} 
Length: \\
144.5 \\
Breadth: 50 \\
Hat length: \\
29 \\
Thickness: 2 \\
\end{tabular} & $\begin{array}{l}\text { Length: } 172 \\
\text { Breadth: } 50 \\
\text { Hat length: } \\
29 \\
\text { Thickness: } 2\end{array}$ & \begin{tabular}{|c|} 
Length: 55 \\
Breadth: 38 \\
Thickness: 2
\end{tabular} & $\begin{array}{c}\text { Diameter } \\
68\end{array}$ \\
\hline Modified & \begin{tabular}{|c|} 
Length: 90 \\
Breadth: \\
145 \\
Thickness: \\
3 \\
\end{tabular} & \begin{tabular}{|c|} 
Length: 144 \\
Breadth: 74 \\
Hat length: \\
29 \\
Thickness: 3 \\
\end{tabular} & \begin{tabular}{|l|} 
Length: 174 \\
Breadth: 74 \\
Hat length: \\
29 \\
Thickness: 3 \\
\end{tabular} & \begin{tabular}{|c|} 
Length: 55 \\
Breadth: 38 \\
Thickness: 3
\end{tabular} & $\begin{array}{c}\text { Diameter } \\
68\end{array}$ \\
\hline
\end{tabular}

\section{Results and Discussion}

\subsection{Original model results}

\subsubsection{Modal Analysis}

Table 5: Modal Frequency list for the original chassis design

$\begin{array}{rll}\text { Mode } & \text { Frequency } & \text { Eigenvalue } \\ 1 & 2.779492 E+01 & 3.049935 E+04 \\ 2 & 3.385920 E+01 & 4.525985 E+04 \\ 3 & 3.613955 E+01 & 5.156145 E+04 \\ 4 & 4.513406 E+01 & 8.042084 E+04 \\ 5 & 4.830037 E+01 & 9.210921 E+04 \\ 6 & 5.587648 E+01 & 1.232588 E+05 \\ 7 & 7.606111 E+91 & 2.283942 E+05 \\ 8 & 7.972582 E+01 & 2.50933 \theta E+05 \\ 9 & 8.212186 E+01 & 2.662425 E+05 \\ 10 & 8.767221 E+01 & 3.034476 E+05 \\ 11 & 9.102662 E+01 & 3.271121 E+05 \\ 12 & 9.611039 E+01 & 3.646704 E+05\end{array}$

The modal analysis was performed to obtain results for 12 modes of the chassis and the list of frequencies and eigen values are given in table 5 . it shows that the minimum frequency is $27.795 \mathrm{~Hz}$ and the maximum frequency is $96.110 \mathrm{~Hz}$ which implies that the selected engine or the overall vibration affecting the vehicle should be either lower or higher than the given range.

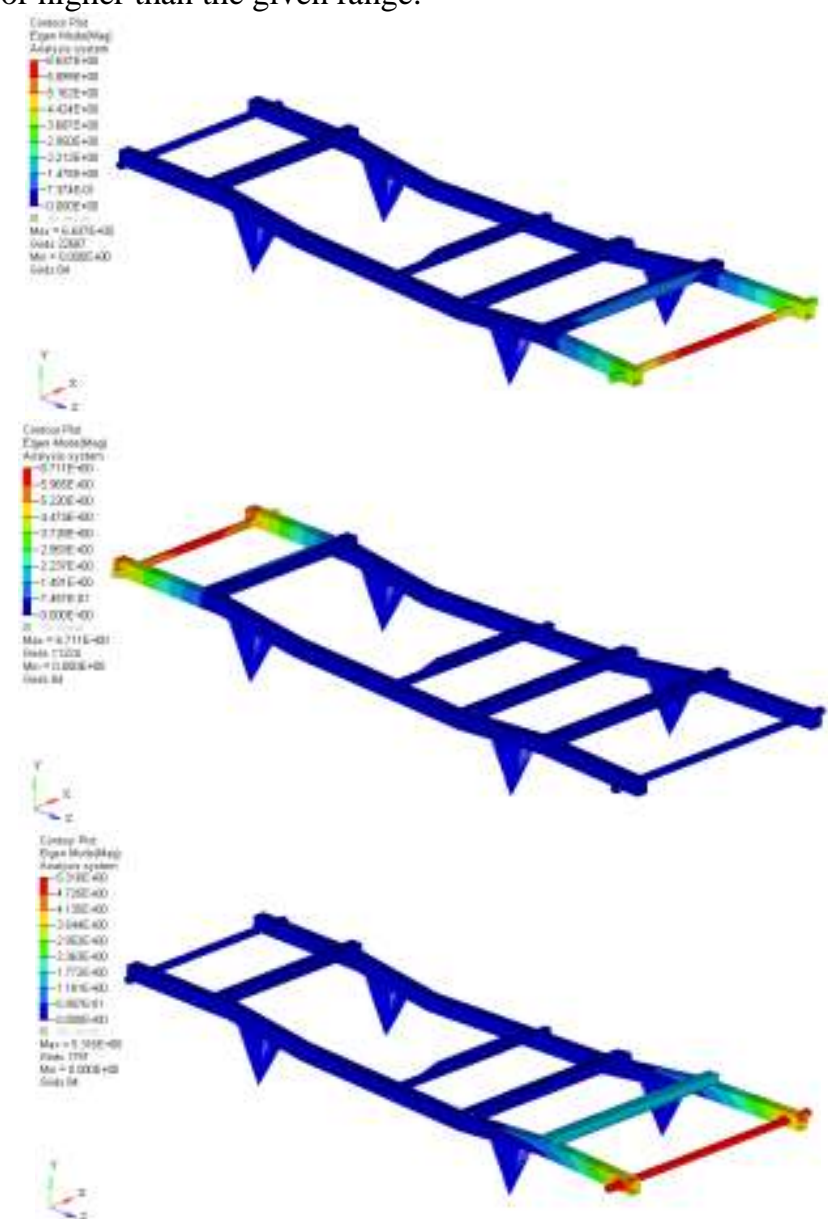

Figure 7: Mode shapes of the original chassis design

\subsubsection{Static analysis}

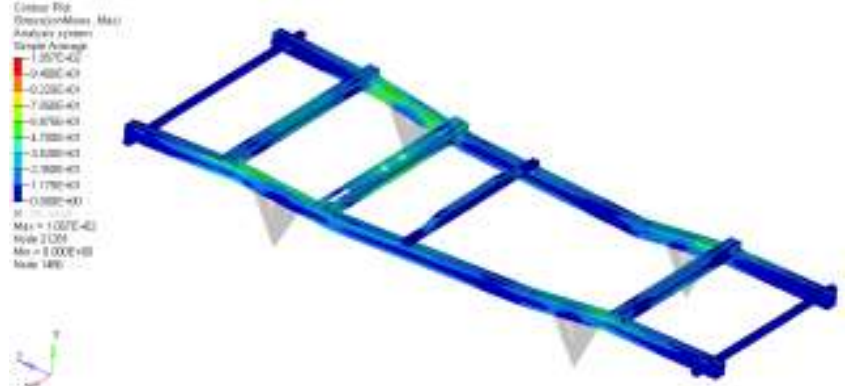

Figure 8: Stress plot for chassis when the vehicle is moving on a straight road

Figure 8 show the stress plot for the chassis when the vehicle is moving on a straight road. The maximum stress value is seen to be $105.7 \mathrm{MPa}$ which is far below the yield strength of the material used for the construction of the chassis. The maximum stress only occurs near the axle region of the chassis. 


\section{International Journal of Science and Research (IJSR) \\ ISSN (Online): 2319-7064}

Index Copernicus Value (2016): 79.57 | Impact Factor (2015): 6.391

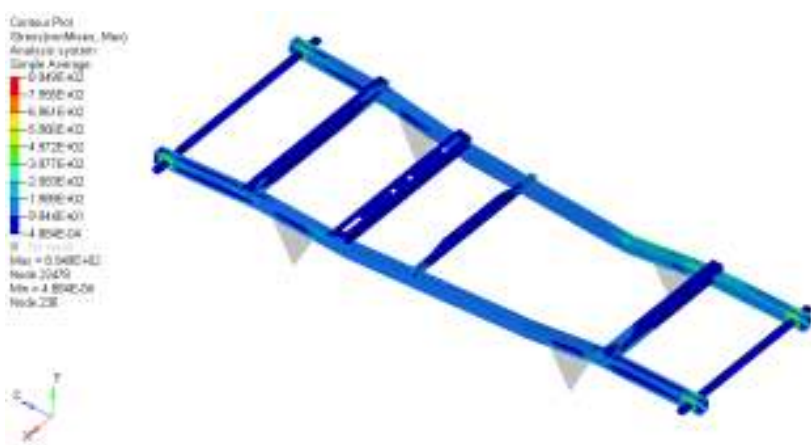

Figure 9: Stress plot for chassis of the vehicle during left cornering

Figure 9 show the stress plot for the chassis when the vehicle is on a left turn with GVW. The maximum stress value is seen to be $894.9 \mathrm{MPa}$ which is more than three times higher than the yield strength of the material used for the construction of the chassis.

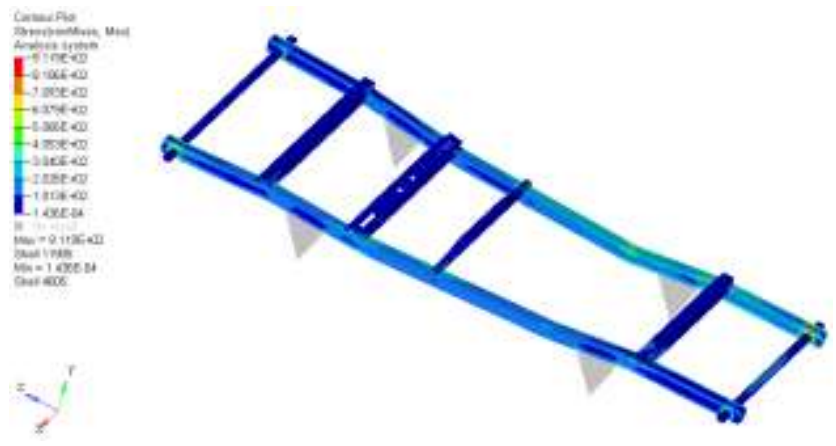

Figure 10: Stress plot for chassis of the vehicle during right cornering

\subsection{Modified model results}

\subsubsection{Modal Analysis}

Table 6: Modal Frequency list for the original chassis design

$\begin{array}{rll}\text { Mode } & \text { Frequency } & \text { Eigenvalue } \\ 1 & 2.604916 \mathrm{E}+01 & 2.678843 \mathrm{E}+04 \\ 2 & 3.371973 \mathrm{E}+01 & 4.488775 \mathrm{E}+04 \\ 3 & 3.464271 \mathrm{E}+01 & 4.737872 \mathrm{E}+04 \\ 4 & 4.148526 \mathrm{E}+01 & 6.794342 \mathrm{E}+04 \\ 5 & 5.814594 \mathrm{E}+01 & 1.334746 \mathrm{E}+05 \\ 6 & 6.246700 \mathrm{E}+01 & 1.540498 \mathrm{E}+05 \\ 7 & 6.842009 \mathrm{E}+01 & 1.848106 \mathrm{E}+05 \\ 8 & 7.866410 \mathrm{E}+01 & 2.442941 \mathrm{E}+05 \\ 9 & 8.073312 \mathrm{E}+01 & 2.573139 \mathrm{E}+05 \\ 10 & 8.674076 \mathrm{E}+01 & 2.970340 \mathrm{E}+05 \\ 11 & 1.014652 \mathrm{E}+02 & 4.064378 \mathrm{E}+05 \\ 12 & 1.096836 \mathrm{E}+02 & 4.749450 \mathrm{E}+05\end{array}$

The modal analysis was performed to obtain results for 12 modes of the chassis and the list of frequencies and eigen values are given in table 6 . it shows that the minimum frequency is $26.049 \mathrm{~Hz}$ and the maximum frequency is $109.684 \mathrm{~Hz}$ which implies that the selected engine or the overall vibration affecting the vehicle should be either lower or higher than the given range.

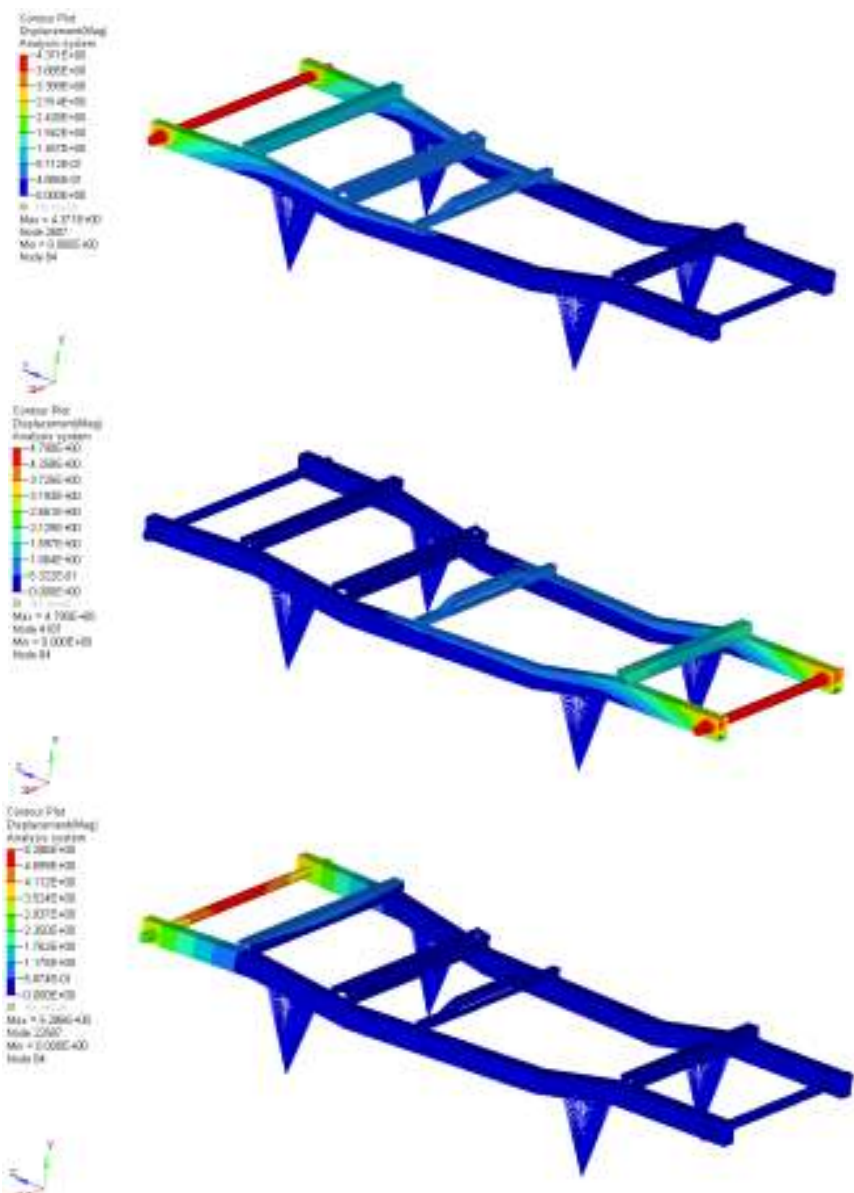

Figure 11: Mode shapes of the modified chassis design

\subsubsection{Static analysis}

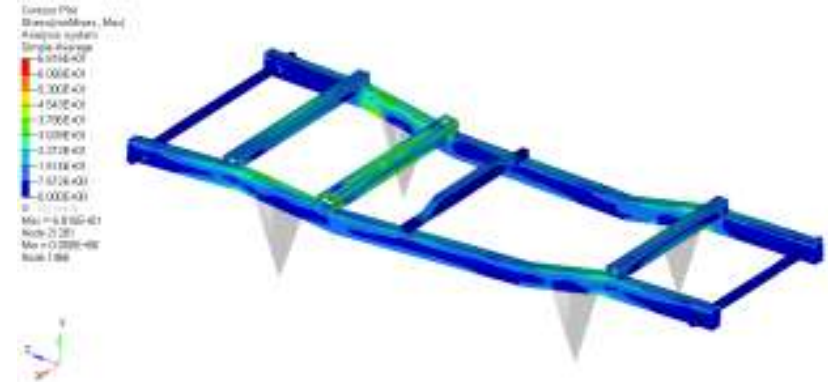

Figure 12: Stress plot for chassis when the vehicle is moving on a straight road

Figure 12 shows the stress plot for the chassis when the vehicle is moving on a straight road. The maximum stress value is seen to be $68.15 \mathrm{MPa}$ which is far below the yield strength of the material used for the construction of the chassis. The maximum stress only occurs near the axle region of the chassis.

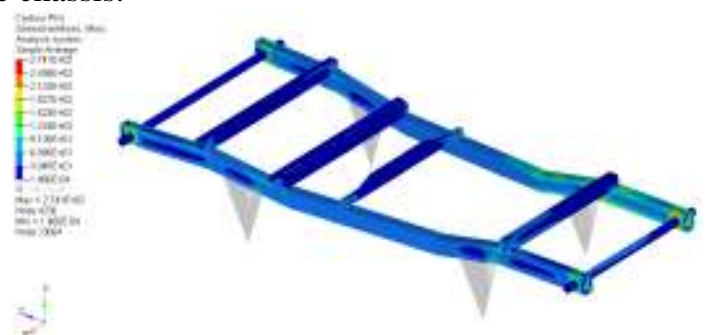

Figure 13: Stress plot for chassis of the vehicle during left cornering 


\section{International Journal of Science and Research (IJSR) \\ ISSN (Online): 2319-7064}

Index Copernicus Value (2016): 79.57 | Impact Factor (2015): 6.391

Figure 13 show the stress plot for the chassis when the vehicle is on a left turn with GVW. The maximum stress value is seen to be $274.1 \mathrm{MPa}$ which is below the yield strength of the material used for the construction of the chassis.

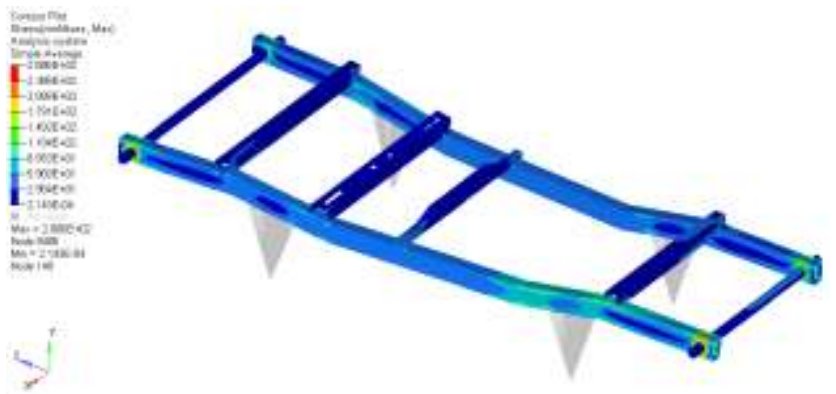

Figure 14: Stress plot for chassis of the vehicle during right cornering

Figure 14 show the stress plot for the chassis when the vehicle is on a right turn with GVW. The maximum stress value is seen to be $268.6 \mathrm{MPa}$ which is below the yield strength of the material used for the construction of the chassis.

Table 7: Stress comparison of original and modified chassis

\begin{tabular}{|c|c|c|c|}
\hline & Original Chassis & Modified Chassis & Ratio \\
\hline Straight & $105.7 \mathrm{MPa}$ & $68.15 \mathrm{MPa}$ & 1.551 \\
\hline Left Turn & $894.9 \mathrm{MPa}$ & $274.1 \mathrm{MPa}$ & 3.265 \\
\hline Right Turn & $911.9 \mathrm{MPa}$ & $268.6 \mathrm{MPa}$ & 3.395 \\
\hline
\end{tabular}

\section{Conclusion}

In this present work, a transport vehicle chassis was to be developed to withstand the routine load applied on it. The chassis was designed in such a way as to provide adequate space for the engine, driver cabin and the carrier. Different sections were used to assist in distributing the load equally to all parts of the chassis.

After the chassis was designed the loads were calculated and prepared for pre-processing. During pre-processing, the model was discretized using $1 \mathrm{D}, 2 \mathrm{D}$ and $3 \mathrm{D}$ elements to simulate the structures actual performance. The loads were applied and model was analysed. Four different analyses were conducted on the model.

- Modal analysis

- Static analysis on a straight road

- Static analysis during left cornering

- Static analysis during right cornering

The first set of results was not optimal for use as they showed a very stress value and the design had to be modified. The second set of results is more promising in withstanding the loads applied and the following conclusions can be drawn.

- The modal analysis of the original and the modified design showed that the modified design has a slightly higher frequency rating than the original model.

- The static analysis done to simulate the vehicle moving on a straight road yielded satisfactory results in both the designs.

- During a left turn, the original model showed a very high stress value whereas the modified model results were well within the yield strength.
- During a right turn, the original model showed a very high stress value whereas the modified model results were well within the yield strength.

- The modification in the design of the chassis and the reduction in the stress values indicate that the load carrying capacity of the modified chassis has been increased.

\section{References}

[1] Process-Mechanical Properties Relationship for an Aircraft Wing Spar: Comparison of Prepreg, Lri and Rfitechniques Pascal Casari, Bernard Stervinou, Peter Davies, Dominique Choqueuse.

[2] Finite Element Analysis of Inter Spar Ribs of Composite Wing of Light Transport Aircraft against Brazier Load Polagangu James, D. Murali Krishna, Gaddikeri Kotresh and Byji Varughese.

[3] Study of Weight Optimization on Spar Beam for the Wing of an Aircraft N.Maheswaran S.P.Venkatesan M.S.Sampath Kumar G.Velmurugan N.Sathishkumar M.Priya.

[4] Optimization Of Aircraft Wing With Composite Material Shabeer Kp1, Murtaza M A

[5] Optimal Topology of Aircraft Rib and Spar Structures under Aeroelastic Loads Bret K. Stanford.

[6] Statistic and Dynamic Analysis of Typical Wing Structure of Aircraft using Nastran. Mr. Pritish Chitte, Mr. P. K. Jadhav, Mr. S. S. Bansode.

[7] Design and Structural Analysis of the Ribs and Spars of Swept Back Wing Mohamed Hamdan A, Nithiyakalyani S.

[8] Analysis Of The wing box With Spliced Skin and Estimation of the Fatigue Life For The wing box $\mathrm{S}$ Sarath1, Jason Cherian Issac and K E Garish.

[9] Design of an Aircraft Wing Structure for Static Analysis and Fatigue Life Prediction A. Ramesh Kumar S. R. Balakrishnan S. Balaji.

[10] Fatigue, residual strength and non-destructive tests of an aging aircraft's wing detail K. Koski A. Siljander a, M. Backstrom, S. Liukkonen a, J. Juntunen a, M. Sarkimo a, K. Lahdenpera J. Tikka b, R. Lahtinen.

[11] Multidisciplinary design optimization of blended-wingbody transport aircraft with distributed propulsion $\mathrm{L}$. Leifsson A B A. Kob, W.H. Mason b, J.A. Schetzb, B. Grossman b, R.T. Haftkac.

[12] Design and Stress Analysis of a General Aviation Aircraft Wing. Ghassan M. Atmeh, Zeaid Hasan and Feras Darwish Jordan University of Science and Technology, Irbid, Jordan, 2Texas A\&M University, College Station, Texas.

[13] Ashley, on making things the best-aeronautical uses of optimization, Journal of Aircraft 19 (1) (January 1982) 5-28 